\title{
Injury prevention in the UK-the European dimension
}

\author{
Jo Sibert, David Stone
} The UK, the European Union, and child
safety policy

The European Union (EU) plays an increasingly important part in the everyday lives of people in all its 15 member states. In the UK, we are beginning to realise that what happens in Brussels is as important as what happens in London, Edinburgh, Cardiff, or Belfast. This is certainly true of injuries to children. Moreover, the impending constitutional changes within the UK will inevitably have repercussions both for the way that policies are developed in England, Scotland, Wales, and Northern Ireland. It will also effect the relationships of these countries to European institutions. While this section adopts a UK perspective on Europe, we recognise that some or all of the constituent parts of the UK may feel the need to develop their own child safety policies to reflect their distinctive needs.

There are two prerequisites for the development of a comprehensive and effective strategy for child injury prevention in Europe. First, we must have a means of determining the epidemiology of these injuries and monitoring trends throughout the continent. Unfortunately, the information that allows us to compare injury rates in European countries is extremely limited. Second, the advent of the single market implies that the safety of products for children should be considered on an all-European basis rather than a single country one. Despite this, there is much evidence that child safety has a low priority in the single market and that in many important areas there is no harmonisation of safety policies and regulations. ${ }^{1}$ These twin themes of epidemiology and policy harmonisation will recur throughout this section.

Health, University of Wales College of Medicine, Llandough Hospital, Penarth CF64 2XX J Sibert

PEACH Unit, Department of Child Health, University of Glasgow, Royal Hospital for Sick Children, Glasgow D Stone

Correspondence to: Professor Sibert (e-mail: sibert@cardiff.ac.uk).

\section{Trans-European networking for injury prevention}

The EU also offers us the opportunity to work and learn together in preventing injuries through the creation of professional and academic networks for information exchange, research, training, and policy development. Such networking remains relatively rare. Both authors have, however, recently participated in European groups that have been examining the problem of injuries to children and young people. These are:
- European Review of Injury Surveillance and Control (EURORISC) project (DS).

- Confederation of European Specialists in Paediatrics (CESP) (JS).

We will briefly describe these activities and then consider the issues they raise in relation to the protection of European children from injury under five headings:

- The data on childhood injury available throughout Europe.

- Examples of good practice and networking.

- Action and regulations on specific injury problems.

- Research on injury prevention.

- The role of communities.

EUROPEAN REVIEW OF INJURY SURVEILLANCE AND CONTROL PROJECT

In the wake of the Maastricht Treaty's amendment of Article 129 of the Treaty of Rome, a public health policy development exercise was initiated by the European Commission (EC). ${ }^{2}$ One of the recommendations of the working group on injuries was that collaborative research networks be established in Europe. In response, the EURORISC project was conceived. The EURORISC project is a transnational concerted action funded by the EC. Its aim is to review current practice and future requirements for injury surveillance and control in the EU. ${ }^{3}$ With participants from most of the EU member states, EURORISC is a collaboration of injury experts who are committed to the improvement of local, national, and European injury surveillance systems. The twin objectives of its initial phase were:

- To describe the contemporary epidemiology of injury in the EU.

- To identify current injury surveillance and control activities in the EU.

Data were collated from a range of sources including the World Health Organisation, EUROSTAT (the main statistical information office of the EC), the European Home and Leisure Accident Surveillance System (EHLASS), and national governments.

CONFEDERATION OF EUROPEAN SPECIALISTS IN PAEDIATRICS

CESP brings together the professional associations and colleges for paediatricians of the 15 countries of the EU. CESP was concerned at the level of accidents to children and young 
people in Europe. Directorate General V of the EU therefore asked CESP to undertake a collaborative study on accidents to children and young people at home, at leisure, and at sport. It covered all 15 countries of the EU. The group who undertook this study consisted of Jean Lavaud and Michel Manciaux from France, Jean Claude Schaack, Secretary General of the CESP from Luxembourg, and Jo Sibert from the UK.

The objectives of the CESP group were:

- To describe and summarise the data on childhood accidents available to member states on the occurrence of these accidents. To comment on the quality of those data.

- To describe policies and programmes of member states for the prevention of these accidents.

- To evaluate the effectiveness of these policies, identifying also those features likely to be worthy of consideration by other member states.

The group identified national correspondents in the 15 countries of the EU with the help of CESP. They received a detailed plan of work together with a letter asking them whether they would cooperate in the project. All agreed. The group produced a protocol for collecting the basic information. Translated into appropriate languages, it was circulated to the correspondents in November 1996. We analysed epidemiological data to highlight particular areas of concern and to permit comparisons over time. We reviewed national publications, as well as the international literature, to judge the effectiveness of different approaches to injury prevention in Europe. We identified examples of good practice that could potentially be adopted by other countries and the EU as a whole. Directorate General V published the report in $1997 .^{4}$

\section{Injury data available in the EU}

EURORISC FINDINGS

The initial task of EURORISC was to try to describe the epidemiology of injury in the (current) member states of the EU. The most readily available data related to mortality.

The data presented here seek to describe injury mortality patterns in the population of children (0-14 years) in the EU for the period 1984-93. ${ }^{5}$ The external cause codes for all unintentional E800-E949 were examined. For the analyses of cause specific injury rates by country, Luxembourg was excluded due to its very small number of injury deaths.

Between 1984 and 1993, 61707 children resident in the EU died as a result of an unintentional injury. Of these, $64 \%$ were male. By the end of the study period, this represented over $30 \%$ of the total childhood mortality in the EU.

The most frequent causes of death due to injury are shown in table 1 .

These data confirm previous studies of mortality in Europe that almost half of all childhood injury deaths are due to transport
Table 1 Principal causes of deaths due to injury, EU children 0-14 years, 1984-93

\begin{tabular}{lr}
\hline & No (\%) \\
\hline Transport accidents & $29234(47)$ \\
Drownings & $7105(12)$ \\
Fire and flames & $3602(6)$ \\
Falls & $3159(5)$ \\
Miscellaneous & $18607(30)$ \\
\hline
\end{tabular}

Table 2 Age specific (0-14 years) mortality rates, 14 EU member states, 1993 (unless otherwise stated)

\begin{tabular}{lll}
\hline Member state & $\begin{array}{l}\text { No of injury } \\
\text { deaths }\end{array}$ & Rate/100 000 \\
\hline Portugal & 255 & 13.8 \\
Belgium & $184^{\star}$ & 10.2 \\
Spain & $692 \dagger$ & 9.7 \\
Austria & 125 & 8.9 \\
Greece & 156 & 8.6 \\
France & 899 & 8.1 \\
Ireland & $74 \dagger$ & 7.9 \\
Germany & 970 & 7.3 \\
Finland & 69 & 7.1 \\
Denmark & 61 & 6.9 \\
Italy & 586 & 6.6 \\
Netherlands & 174 & 6.2 \\
UK & 599 & 5.3 \\
Sweden & 81 & 5.0 \\
\hline
\end{tabular}

$\star 1989 ; \nmid 1992$.

accidents, $95 \%$ of these involving motor vehicles. $^{6}$

All member states reported a decrease in age standardised injury mortality rates over the study periods. The largest fall was in the UK $(-47 \%)$ and the smallest in Finland $(-12 \%)$. Overall the greatest decline was for motor vehicle traffic accidents $(-34 \%)$.

The ranking of the member states by age specific injury mortality rates is shown (for the latest available year) in table 2. The rate of the highest ranked country (Portugal) was more than two and a half times that of the lowest (Sweden). The rate of the UK was almost as low as that of Sweden.

Two countries had the highest ranking of mortality in 1993 for specific causes of injury death: Portugal (motor vehicle traffic accidents, fire and flames) and Austria (drownings, falls). The UK had a low ranking for all the specific causes except fire and flames, the death rate from which was higher only in Portugal.

In summary, the preliminary conclusions from the early EURORISC analyses suggest that

- Injuries continue to be the leading cause of death in childhood throughout the EU.

- Transport accidents are the major cause of child injury death throughout the EU.

- Wide variations in child injury mortality between EU countries are apparent.

- All EU countries have experienced a decline in child injury mortality in recent years.

- The UK has a lower rate of child injury mortality (all causes) compared to all other EU countries except Sweden.

- The UK has a relatively high rate of child injury mortality due to fire and flames.

- The UK has experienced the largest recent fall in child injury mortality in the EU.

A major problem in interpreting these intercountry variations lies in heterogeneity of 
injury definitions, certification, coding, and classification practices around the EU. This is particularly but not exclusively true of morbidity data such as those relating to hospitalisations and attendances at hospital accident and emergency departments. Some degree of standardisation of recording of the latter has been achieved by EHLASS and other injury surveillance systems. These will be reviewed in a later phase of the EURORISC project.

\section{CESP FINDINGS}

The CESP group was disappointed by the quality of the data in EU countries. This was the case with both mortality and morbidity.

As regard mortality, although the International Classification of Diseases 10th revision (ICD10) has been in existence since 1992, it is little used. We found that ICD9 is used mainly still in the EC leading to difficulties of comparison. There is often insufficient detail in both ICD9 and ICD10 for adequate analysis of deaths for use in prevention. An example is deaths from drowning. To develop an adequate preventive strategy, we must know the site and mechanism of drowning. This is unavailable in most countries.

We were also concerned with the ascertainment of some of deaths that formed the basis of the mortality figures we collected. For instance we questioned whether some southern European countries really had lower rates of drowning death than, for instance, Sweden.

We were also disappointed that we had found sparse information on the morbidity (including long term sequelae) from injuries in Europe with the exception of:

- A few organised national or regional programme of surveillance.

- A few specific clinically based studies in research programmes.

- EHLASS.

Although EHLASS provides a great deal of information, it has limited value for prevention because of its strong emphasis on product safety, its restriction to home and leisure injuries, and its variable methodology in different countries.

Examples of good practice and networking It is always difficult to compare countries of widely varying populations. In the EU, seven countries have a population of between 5 and 10 million and some others have less than 5 million. However, the CESP group found several good examples of networking in the prevention of accidents in countries of the EU. The progress made by the Child Accident Prevention Trust in the UK and the Child Environment Council in Sweden is well known. They have both been in existence for some years. CESP was also impressed with more recently formed organisations. A particularly striking example of good practice in the last 10 years is Austria. The Finnish Central Union for Child Welfare and the Portuguese Associcao para e Promacao de Securanca Infantil are also working well under the same pattern.
In addition to national organisations, a few regions in Europe have child safety groups. These include Brandenburg, Catalonia, Scotland, Venetia, and Wales. These regional organisations fit well with the increasingly devolved political structures throughout the EU.

\section{Action and regulations on specific injury problems for child safety}

The CESP group found that at least eight areas of child safety where proven preventive measures are used differently throughout the community despite the single market. These are:

- Child resistant containers and packaging.

- Smoke detectors and house fires.

- Drowning.

- Farm injuries.

- Playground injuries.

- Babywalkers.

- Glass injuries.

- Bath scalds.

CHILD RESISTANT CONTAINERS AND PACKAGING Accidental poisoning is predominantly seen in children under the age of 5 years but older children may be involved if they are developmentally delayed. The peak age is between 1 and 4 years. This is a key area because of the preventive value of child resistant containers and packaging.

Children may take a variety of substances accidentally. These are conveniently divided into medicines (prescribed and nonprescribed), household products, and plants. The majority of children who take poisons do not have serious symptoms. Medicines may be of low toxicity, for example oral contraceptives or antibiotics; intermediate toxicity-which may cause symptoms in young children; or of potential high toxicity. ${ }^{7}$ Many of the household products children take may be relatively non-toxic, however a few such as caustic soda, soldering flux, and paint stripper may cause serious harm.

Mortality from accidental poisoning is a rare event and is not a satisfactory way of assessing the extent of the problem. Morbidity has been estimated in a number of ways:

- Hospital presentations, either by EHLASS or by specific studies.

- Hospital admissions such as in Finland. ${ }^{8}$

- Contact with poison centres (Italy and Sweden).

Much of this information contains no details on packaging, so is of limited use for preventive purposes.

Dr Jay Arena in Durham, North Carolina, first suggested child resistant containers (CRCs) in 1959. ${ }^{9}$ These containers were evaluated in a community in the United States by $S_{c h e r z}{ }^{10}$ and found to be successful. They were then introduced for aspirin preparations into the United States with successful results. ${ }^{11}$ Thereafter, CRCs were progressively introduced in some countries in Europe. There have been few studies evaluating these changes. 
- In the UK CRCs were introduced by regulation in 1976 for junior aspirin and paracetamol preparations. This resulted in a fall in admissions of children less than 5 years after salicylate poisoning. ${ }^{12}$ In 1982 a voluntary agreement between the British government and the Royal Pharmaceutical Society proposed that all prescribable solid dose medication would be placed in CRCs or safety packaging with exceptions only for the elderly and infirm. In 1985, the Department of Trade and Industry introduced regulations for a number of household products to be sold in CRCs.

- In a study in Ireland, where there are no CRC regulations, ${ }^{14}$ only $8.5 \%$ of the medications involved were in CRCs. Twenty per cent were in blister packs or strips. The authors proposed a two phase approach to poisoning prevention: more widespread use of CRCs and public education on safe storage of medicines.

CESP collected information on CRCs and packaging regulations from the 15 countries in the EU. We found that some countries appear to have no regulations at all, some have regulations for some household products, and some have regulations for some medicines and some household products. In other words, despite good evidence that CRCs and packaging prevent childhood poisoning, their use is very variable. Those regulations that involve consumer products should be harmonised throughout the EU.

SMOKE DETECTORS AND HOUSE FIRES

Fires and flames are a significant cause of death in childhood in many countries in Europe. The majority of children die in conflagrations in private dwellings, often in conditions of poverty. Many children die from gas and smoke inhalation rather than by direct heat. While there has been a striking fall in the number of children who have died from fire in recent years, the death rate from fires remains unacceptably high. A major component of the reduction has been the fall in the number of deaths from the ignition of clothing following flame proofing regulations and the reduction of open fires. There have been few specific studies of deaths from fire and flame at EU level.

Smoke detectors are widely used in several countries and found to be effective ${ }^{15}$ (see section 3) and are becoming more widespread in Europe. They have an important role in the prevention of conflagrations and their use should be enforced both in public and private housing. At present these regulations throughout the community tend to involve public buildings rather than homes where children live. We believe that countries throughout the EU should have regulations for smoke alarms in housing.

DROWNING

Drowning is one of the commonest causes of accidental death in children in many countries in Europe. The majority of the countries in the EU just identify "drowning" as the cause of death. We believe, however, that to maximise the potential for prevention and to evaluate trends there should be a more detailed analysis that includes the site and mechanisms for drowning. We only found evidence of such studies in Finland, the Netherlands, the UK, and Ireland.$^{16}$ Each site of drowning incident has a definite age range and corresponds to a stage in child development:

- Babies who cannot protect themselves when they fall in bath water.

- Toddlers who wander off and drown in accessible water (garden ponds in the UK, drainage ditches in the Netherlands, and domestic swimming pools in southern Europe).

- Older children who die while swimming when unsupervised.

There is evidence that supervision of swimming and water activity prevents drowning. In the UK, only one child dies a year in municipal pools where direct observation of swimming is enforced by the Health and Safety Executive; whereas many die in rivers, lakes, and canals where there is no supervision. ${ }^{16}$ Certainly, there has been an overall fall in the number of deaths of children from drowning which has coincided with better supervision. Some European countries now place a strong emphasis on the supervision of swimming:

- Austria has national swimming pool regulations for supervision.

- France has supervision of sea swimming by the national police (CRS).

- Germany has national swimming pool regulations for supervision.

- Greece has national swimming pool regulations for supervision and supervision of paying beaches.

- In the UK, observation of swimming in municipal pools is enforced by the Health and Safety Executive.

Lifeguard supervision should be extended to private pools and open water where swimming is common.

There is clear evidence from work by consumer organisations and from press reports that some children drown in hotel pools while on holiday. They are likely to be preventable if these pools were supervised. CESP had difficulty obtaining accurate information on these children who may be reported either in the country of residence or the country of death. Freedom of movement is a major principle of the EU. This is clearly an issue for the EU in future. Progress might be achieved by action by tour operators.

The CESP group had clear evidence from its correspondents that domestic pools are becoming more common throughout the EU particularly in the warmer south. There is little to no information on how many children drown in these pools. We do know, however, that in Australia and in the USA drowning of toddlers in these pools is a very common problem.

There is evidence from Australia that fencing domestic pools can prevent drowning. Pearn and Nixon compared drownings from private swimming pools in Brisbane and in Canberra. ${ }^{17}$ In Canberra, swimming pools by law had to be 
fenced but there was no such legal sanction in Brisbane at the time of the study: only one child died in the Australian capital from a swimming pool accident over a five year period, compared with 55 in Brisbane. Fencing has been introduced by regulation in parts of Australia, South Africa, New Zealand, and parts of the United States.

We do not believe that, apart from Sweden, any country in the EU has regulations for fencing domestic swimming pools. Research is needed urgently on this subject, both on the size of the problem in Europe and the use of fencing

PREVENTING FARM INJURIES

Agriculture is an essential part of the work of the EU. Recently much attention has been paid to bovine spongioform encephalitis. However, many more people have died from agricultural injuries than new variant Creutzfeldt-Jakob disease.

Agriculture is unique in that a significant component of the work force is made up of children under the age of 16 , especially at times of peak activity in the farming year. For children, the most significant feature in considering farm related accidents is that the farm is perceived as a place of excitement and adventure. For many, the farm is often also the home, or the place where holidays are taken. CESP had evidence from its correspondents that the farm may be a dangerous environment for children. There are a number of studies and preventive strategies in the EU:

- In Denmark, the incidence of farm injuries in children on farms fell from 6/1000 (1984-89) to 4/1000 (1990-94). In Denmark, all injuries have to be reported to the Directorate of the Working Environment.

- In Finland, every year at least four or five people under the age of 20 die due to injuries on farms. Two or three of them are under 10 years old. In addition to these fatalities hundreds or perhaps thousands of young people are injured, some of them disabled for the rest of their lives.

- Doyle and Conroy in Ireland reviewed farm injuries and found significant unrecognised problems. ${ }^{18}$

- Schelp in Sweden found that the dominant types of injuries were falls, crushes, and eye injuries. ${ }^{19}$

- In the UK, Cameron et al reviewed the problem of farm accidents to children by a 12 month prospective study in the county of Dyfed, finding one child in 50 living on a farm presents with a farm related accident in each year. ${ }^{20}$ None of these non-fatal cases had been reported to the Health and Safety Executive, although they should have been by law. There is also legislation to prohibit the driving of tractors by children under the age of 13 and to prohibit the riding of any persons as passengers on tractors, trailers, or other field implements. This has been in place for many years but is often ignored.
There is thus a clear need within the EU to collect data, share experience, and develop effective programmes to prevent these injuries.

\section{PLAYGROUND INJURIES}

Playground safety is another key area for children in Europe. Playgrounds were originally developed to offer play opportunities for children in an increasingly industrialised society during the nineteenth century. They still have this important role. Their safety is important not only in prevention of injuries but also because families need the assurance that it is safe for their children to play. There has been much work in developing safer equipment and surfaces and in producing acceptable safety standards. European standards for playground safety are currently being developed (CEN/ TC/136 SC 1). However these and other standards have largely been developed in the laboratory and there has been little analysis of real children having real injuries on real playgrounds in Europe:

- Mulder and colleagues studied swing accidents in the EU through EHLASS. ${ }^{21}$ Eight countries provided information on a total of more than 5000 accidents. Based on this information it was concluded that every year in the EU 70000 people are treated at an accident and emergency department for an injury due to a swing, that is 11 victims per 10000 children up to 15 years of age.

- In the UK, the Leisure Accident Surveillance System (LASS) estimated that there are 24000 playground injuries each half year in England and Wales. ${ }^{22}$

- Mott and colleagues in the UK reviewed playground injuries in one city: they found $1.5 \%$ of hospital attendances were due to injuries sustained in a playground. ${ }^{23} 24$ They found that safety surfacing was protective against injuries to children on playgrounds but that a rubberised impact absorbing surface was safer than bark. They found differences in the risks to children having injuries on different pieces of equipment. When a child fell from equipment the probability of receiving an injury on monkey bars was twice that on a climbing frame and seven times on a swing or slide. Monkey bars (overhead ladders) were a particular problem for children probably because of the upper body strength and coordination needed. The analysis of maximum fall heights by Mott and colleagues clearly showed that the risk of injury was greatly increased at heights of over 1.5 metres. ${ }^{24}$ This confirms the findings of Chalmers and his colleagues in an elegant case-control study from New Zealand. ${ }^{25}$

Playground design involves balancing the play value of a playground with safety issues. Safety standards in playgrounds are important and the development of European standards present children with opportunities and threats for their safety. They are, at present, developed on physical standards only and not on epidemiological data. The CESP group be- 
lieves that paediatricians must be involved with the development of European standards.

There is increasing evidence that installing safety surfaces alone may be insufficient to prevent childhood injuries. There is also evidence that height of equipment is a critical factor in the aetiology of playground injuries with heights of over 1.5 metres being dangerous. The CESP team believes that the plans to place the maximum fall height in European standards at 3 metres or more may place children at unacceptable risks.

\section{BABYWALKERS}

The danger of falls from babywalkers has been highlighted by a number of studies throughout the community.

- In Greece Petridou and colleagues identified the incidence of babywalkers injuries as $3.5 / 1000$ per year. ${ }^{26}$ They found that they do not have any benefit for child development.

- In the UK Gleadhill and colleagues found babywalkers were a major hazard without benefit. ${ }^{27}$

Babywalkers offer risks of injury but no benefit to children. There are EU regulations on babywalkers but many do not comply with them. There is strong case for the outlawing of these devices.

SCALDS

Scalds are among the most distressing injuries a child can receive. They do not often cause death but they do cause considerable pain, they often need prolonged treatment, and they often result in life long scarring. This scarring and deformity may result in considerable emotional difficulties that can affect the child's whole life. It would be much better if we could prevent these serious injuries rather than have to treat them. Eadie et al at the Welsh Centre for Burns and Plastic Surgery in the UK, have been able to review what progress we have made in prevention over the last 35 years. ${ }^{28}$ They compared the pattern of scalds in $1956^{29}$ with $1984^{30}$ and $1991 .^{28}$ Sadly, it appears that there had been no reduction in the numbers of scalds to children at the Welsh Centre. There has been a change in the pattern of these injuries with scalds from hot water from teapots falling and from hot liquids from cups and in baths rising.

The CESP group particularly concentrated on bath scalds, where they believe there is most scope for their prevention. The group heard from their correspondents in various parts of the EU that bath scalds were a problem, but there have been few studies to quantify this or their aetiology.

- In the UK the majority of bath scalds are caused when the child falls in the water. ${ }^{31}$ Yeoh and her colleagues described common patterns of bath water scald injuries in children, examined differences between accidental and non-accidental bath water scalds in children, and examined potential for prevention. Bath scalds were the cause of 14.7 per 100000 children less than 5 years being admitted to the specialist burns unit in a year. The majority of the children were injured by falling in the bath but with some the tap was turned on by children themselves or by siblings.

A reduction in the temperature of tap water entering the bath would prevent these scalds. This can be done either by altering thermostats or by using thermostatic mixer taps for the bath. A study in New Zealand evaluated an educational programme to reduce hot tap water temperatures in homes and found significant decreases in tap water temperature. $^{32}$

There is considerable potential for preventing bath scalds in children throughout the EU by reducing the temperature of water in homes. There needs to be research in the EU on the size of this important problem and into the possible modes of prevention.

GLASS INJURIES

Falls through glass may cause severe lacerations to hands, wrists and arms, and occasionally the face. Severe damage may result from injury to arteries, nerves and tendons, and internal injuries may also be found. The child is usually injured by glass in doors or by low level glazing. A typical story would be a child falling downstairs into a glass door. The sharp, jagged parts of the glass may cause severe lacerations to any parts of the body, particularly the upper limbs.

The CESP group found few specific studies on glass injuries in the EC and a varied pattern of preventive measures.

- In Denmark the incidence of glass injuries varies from 350/100 000 in $10-14$ year old boys to 150/100 $0001-4$ year old boys.

- In Germany there are glass safety regulations 1994.

- In UK Jackson highlighted the problem of glass injuries in childhood and pointed out that most of the severe lesions could be prevented by the use of safety glass. ${ }^{33}$ Safety glass is either laminated, which absorbs impact and is resistant to penetration, or toughened tempered glass that shatters into small cuboid pieces. Other safe alternatives to annealed flat glass are polycarbonate sheet or plastic safety film. Safety glass is covered by the building regulations in the UK.

\section{Research and evidence based policies and programmes}

While epidemiological analysis of different types of injuries is important, it must be complemented by detailed scientific investigation of injury circumstances. Only when it is apparent how and why children are injured are we able to formulate realistic and adapted prevention programmes.

The CESP group was disappointed how few European countries had a programme of research on injury prevention. Very few academic departments of paediatrics and child health in the EU have injury prevention as a main teaching or research theme despite the frequency of death and disability from injuries. 
There have also been very few opportunities for research into injury prevention in childhood through European programmes such as BIOMED. There is a pressing need for the EU to focus research on injury prevention and control in children in the future.

\section{Role of local communities}

The Ottawa Charter for Health Promotion sets out the philosophy behind community development "Health promotion works through concrete and effective community action in setting priorities, making decisions, planning strategies and implementing them to achieve better health. At the heart of this process is the empowerment of communities, their ownership and control of their own endeavours and destinies".

Public health physicians, led by Svanström from the Karolinska Institute in Stockholm, developed the concept of Safe Communities as early as the mid-1970s. In some European countries (for example Austria, Germany, Sweden, UK), there are Safe Community programmes in municipalities and towns which have campaigns with precise objectives. To be efficient they must reach a large proportion of the target population. Then they need to be critically evaluated on a scientific basis. The exchange of experience between countries and between towns for similar programmes can avoid loss of time, loss of money, and save lives. A European network is the ideal tool to make quick progress in a short timescale. EU-wide injury prevention policies and programmes are currently being discussed but progress has been relatively slow. Ultimately, these should act as a catalyst for the extension of the safe community movement.

\section{Conclusions and recommendations}

This review of the European dimension to child injury prevention has highlighted a number of strategic concerns relating to two overarching themes-epidemiological information and collective action. Our epidemiological understanding of the scale, nature, causes, and consequences of childhood injuries is severely constrained by the general lack of appropriate data that can act as the basis to plan, implement, and evaluate preventive measures. Collective action has been modest to date through a combination of political and administrative obstacles despite a growing evidence base for the efficacy of specific measures designed to prevent childhood injuries from a wide variety of causes including those arising from transport, home, leisure, and occupational settings.

In summary the key strategic concerns, related to child injury in the EU, about information and collective action are:

\section{INFORMATION}

- Lack of appropriate routine national data, apart from mortality.

- Limited value of ICD9 and ICD10 for prevention.

- Virtual absence of morbidity data.
- EHLASS data only partially relevant to prevention.

- Little EU-wide research on child injury prevention undertaken.

\section{COLLECTIVE ACTION}

- Paucity of child safety (including community based) networks in EU.

- Limited implementation of preventive measures of known efficacy.

- Lack of harmonisation of EU-wide safety regulations.

- Slow progress in the development of an EU-wide injury prevention policy.

There is thus much more to be done if we are to safeguard Europe's children from injury. There is a need to improve both our information systems and our collective efforts.

In relation to information, we recommend:

- An EU-wide initiative to improve in the scope, detail, and quality of data on mortality and morbidity of childhood injuries.

- A review of ICD and other injury coding systems with reference to their preventive utility.

- The allocation of resources to the further development of EU-wide injury surveillance (including EHLASS).

- A substantial expansion of epidemiological and evaluative research on child injury prevention in the EU.

In relation to collective action, we recommend:

- An acceleration of current efforts to develop an EU-wide policy on injury prevention, with special emphasis on children.

- The creation or extension of professional and academic networks for information exchange, research, training, and policy development.

- An urgent review of the extent to which preventive interventions of known efficacy have been implemented throughout the EU.

- Harmonisation of regulations on child safety throughout the EU within the single market.

- An extension and development of the safe community movement.

\section{Relevance to the UK}

In recent years, the UK has experienced relatively favourable child injury mortality rates compared with other European countries. This should not induce a sense of complacency within UK governmental agencies for several reasons. First, the reasons for this phenomenon are largely unknown and downward trends could begin to rise again in the future. Second, the UK mortality rates for fire and flame related injuries (and other subgroups of causes not shown in this section such as child pedestrian fatalities) are relatively high in European terms. Third, the child injury rates of the constituent countries of the UK may compare less favourably with other EU countries than those of the UK as a whole. Fourth, while some past successes of the UK in reducing 
childhood injury incidence have been demonstrated, it is unclear to what extent this knowledge has been disseminated and applied elsewhere.

Finally, the EC is planning a programme of injury prevention throughout the EU starting in 1999. Children constitute one of the stated priority areas. This could be the launching pad for further substantial progress in avoiding childhood injury in Europe-including the UK - as we enter the new millennium. The UK is well placed to adopt a leadership role in this enterprise the success of which is vital to the safety and wellbeing of future generations of European children.

1 Sibert JR, Kemp A. Child accident prevention in Europe. Maternal and Child Health 1992;17:314-20.

2 Birt CA, Gunning-Schepers L, Hayes A, et al. How should public health policy be developed? A case study in European public health. F Public Health Med 1997;19:2627.

3 Morrison A, Stone D. The European Review of Injury Surveillance and Control (EURORISC) project: a multicentre European study. International fournal for Consumer centre European study.
Safety 1997;4:9-100.

4 Lavaud J, Manciaux M, Schaack J-C, et al. Survey and evaluation of the policies of member states for the prevention of evaluation of the policies of member states for the prevention of
injuries (home, leisure and sport) to children and adolescents in injuries (home, leisure and sport) to children and adolescents in the 15 countries of the EU. Luxembo

5 World Health Organisation. World health statistics annual 1995. Geneva: WHO, 1996.

6 Jansson B, Svanström L. National inequalities in accident mortality among children and adolescents in the European countries. In: Lindstrom B, Spencer N, eds. Social paediatrics. Oxford: Oxford University Press, 1995: 174-91.

7 Sibert JR, Routledge P. Accidental child poisoning - can we admit fewer children with safety? Arch Dis Child 1991;66: 263-6.

8 Laminpaa A, Riihimaki V, Vilska J. Hospsitalisations due to poisoning in Finland. 7 Clin Epidemiol 1993;46:47-55.

9 Arena JM. Safety closure caps. $\mathcal{F} A M A$ 1959;169:1187-8.

10 Scherz RG. Prevention of childhood poisoning. Pediatr Clin North Am 1970;17:713.

11 Clarke A, Walton WW. Effect of safety packaging on aspirin ingestion by children. Pediatrics 1979;63:687-93.
12 Sibert JR, Craft AW, Jackson RH. Child resistant packaging Sibert JR, Craft AW, Jackson RH. Child resistant packaging

13 Jackson RH, Craft AW, Lawson GR, et al. Changing pattern of poisoning in children . BMF 1985;287:1468.

14 Rfidah EI, Casey PB, Tracey JA, et al. Childhood poisoning in Dublin. Ir Med f 1991;84:87-9.

15 US Fire Administration. An evaluation of residential smoke detectors under actual field conditions. Washington, DC: US Fire Administration, 1980. Final report EMW-C-002.

16 Kemp AM, Sibert JR. Drowning and near drowning in children in the United Kingdom. Lessons for prevention. BMF 1992;304:1143-6.

17 Pearn JH, Nixon J. Are swimming pools becoming more dangerous? Med $\mathcal{F}$ Aust 1977;ii:702-4.

18 Doyle Y, Conroy R. Childhood farm accidents; a continuing cause for concern. I Soc Occup Med 1989;39:35-7.

19 Schelp L. The occurrence of farm-environmental injuries in a Swedish municipality. Accid Anal Prev 1992;24:161-6.

20 Cameron D, Bishop C, Sibert JR. Farm accidents in children. BMF 1992;305:23-5.

21 Mulder S, Barrow M, Bay Nielson H, et al. Swing accidents within the European Union. International fournal for Consumer Safety 1995;2:175-89.

22 MacCleary L. Playgrounds-Leisure Accident Surveillance System (LASS). London: Consumer Safety Unit, Department of Trade and Industry, 1989.

23 Mott A, Evans R, Rolfe K, et al. Patterns of injuries to children on public playgrounds. Arch Dis Child 1994;71:32830

24 Mott A, Rolfe K, James R, et al. Safety of surfaces and equipment for children in playgrounds. Lancet 1997;348: $1874-6$.

25 Chalmers DJ, Marshall SW, Langley JD, et al. Height and surfacing as risk factors in falls from playground equipment: a case-control study. Inj Prev 1996;2:98-104.

26 Petridou E, Simou E, Skondras C, et al. Hazards of baby walkers in a European context. Inj Prev 1996;2:118-20.

27 Gleadhill DNS, Robson WV, Cudmore RE, et al. Baby walkers - time to take a stand? Arch Dis Child 1987;62:4914 .

28 Eadie PA, Williams R, Dickson WA. Thirty-five years of paediatric scalds are lessons being learned? Br F Plast Surg 1995;48:103-5.

29 Tempest MN. A survey of domestic burns and scalds in Wales during 1955. BMF 1956;i:1387-92.

30 Green AR, Fairclough J, Sykes PJ. Epidemiology of burns in childhood. Burns 1984;10:368-71.

31 Yeoh C, Nixon J, Dickson W, et al. Patterns of scald injuries to children in the bath. Arch Dis Child 1994;71:156-8.

32 Waller AE, Clarke JA, Langley JD. An evaluation of a program to reduce home hot tap water temperatures. Aust program to reduce home hot Health 1993;17:116-23.

33 Jackson RH. Lacerations from glass in childhood. BMF 1981;283:1310-12. 